\title{
Absolute Bioavailability of Esaxerenone and Food Effects on its Pharmacokinetics After a Single Oral Dose in Healthy Japanese Subjects: An Open-Label Crossover Study
}

\author{
Akifumi Kurata · Hidetoshi Furuie - Tomoko Ishizuka • \\ Takafumi Nakatsu - Takako Shimizu • Manabu Kato • Yasuhiro Nishikawa • \\ Hitoshi Ishizuka
}

Received: February 26, 2019 / Published online: May 22, 2019

(C) The Author(s) 2019

\section{ABSTRACT}

Introduction: To investigate the absolute bioavailability of esaxerenone and the effects of food on its pharmacokinetics (PK) after a single oral dose in healthy Japanese subjects.

Methods: Twenty-four Japanese males aged 20-45 years were randomised to six groups (each $n=4$ ) in this single-centre, open-label, three-way, three-period crossover study. Esaxerenone $(5 \mathrm{mg}$ ) was administered in the fasting state as a single oral dose, single intravenous

Enhanced Digital Features To view enhanced digital features for this article go to https://doi.org/10.6084/ m9.figshare.7969826.

A. Kurata $(\bowtie) \cdot$ T. Ishizuka $\cdot$ T. Shimizu $\cdot$ M. Kato .

H. Ishizuka

Clinical Pharmacology Department, Daiichi Sankyo

Co., Ltd., Tokyo, Japan

e-mail: kurata.akifumi.vz@daiichisankyo.co.jp

H. Furuie

Medical Office, Osaka Pharmacology Clinical

Research Hospital, Osaka, Japan

T. Nakatsu

Biostatistics and Data Management Department,

Daiichi Sankyo Co., Ltd., Tokyo, Japan

Y. Nishikawa

Safety and Risk Management Department, Daiichi

Sankyo Co., Ltd., Tokyo, Japan infusion over $1 \mathrm{~h}$, or in the postprandial state as a single oral dose. Plasma samples were taken before and during the $96 \mathrm{~h}$ after drug administration. Drug concentrations were measured using liquid chromatography-tandem mass spectrometry. PK parameters were calculated using noncompartmental analysis, and safety was assessed.

Results: After fasting intravenous administration, total body clearance was $3.69 \mathrm{~L} \mathrm{~h}^{-1}$ and volume of distribution was $92.7 \mathrm{~L}$. The plasma concentration-time profile of esaxerenone was similar after fasting and postprandial administration. Absolute bioavailability of a single oral 5 -mg dose of esaxerenone was $89.0 \%$ in the fasting state and $90.8 \%$ postprandially. Point estimates (1.010 and 1.019, respectively) and 90\% confidence intervals for geometric least squares mean peak plasma concentrations and area under the plasma concentration-time curve ratios after postprandial versus fasting oral esaxerenone were within the prespecified range $(0.80,1.25)$. No severe adverse events occurred throughout the study.

Conclusions: Esaxerenone has a high absolute bioavailability of approximately $90 \%$ and food has no effect on esaxerenone PK after a single oral dose of $5 \mathrm{mg}$ in healthy Japanese subjects. Additionally, no safety concerns were identified.

Clinical Trial Registration: JapicCTI No. 163452. Funding: Daiichi Sankyo Co., Ltd. 
Keywords: Bioavailability; Drug safety; Food/ herbal drug interactions; Pharmacokinetics

\section{INTRODUCTION}

Patients with hypertension whose blood pressure (BP) cannot be adequately controlled with a single agent typically receive more than one drug for BP control [1-3]. Therefore, for patients with uncontrolled or refractory hypertension, various guidelines (the 2014 Japanese Guidelines for the Management of Hypertension [1] and 2013 European Society of Hypertension/ European Society of Cardiology [4]), metaanalyses [5], large-scale randomised controlled studies [6], and reviews [7] recommend adding an aldosterone blocker to the antihypertensive regimen.

Several studies have demonstrated the benefit of steroidal mineralocorticoid receptor (MR) blockers, such as spironolactone and eplerenone, in the treatment of refractory hypertension; however, use of these agents may be associated with adverse events (AEs) such as hyperkalaemia (spironolactone and eplerenone) and gynaecomastia (spironolactone) [8-10].

Esaxerenone (CS-3150) is a novel, oral, nonsteroidal, selective MR-blocker that was approved in Japan in January 2019 for the treatment of hypertension, and is in development for the treatment of diabetic nephropathy. In preclinical studies in rats, esaxerenone restricted BP elevation caused by deoxycorticosterone acetate/salt-loading, and had cardiorenal protective effects [11]. In a recent, large, phase 2, multicentre, randomised, double-blind, placebo-controlled, 12-week study, 426 Japanese patients with essential hypertension were given $1.25,2.5$, or $5 \mathrm{mg}$ esaxerenone per day, placebo, or 50-100 mg eplerenone per day [12]. Esaxerenone at 2.5 and $5 \mathrm{mg}$ per day reduced sitting BP and 24-h BP compared with placebo, and the incidence of AEs was similar between treatment groups [12].

In animal studies, esaxerenone total body clearance after intravenous (IV) administration was 3.53-6.69 $\mathrm{mL} \mathrm{min}^{-1} \mathrm{~kg}^{-1}$ (rats) and 2.79-$3.69 \mathrm{~mL} \mathrm{~min}{ }^{-1} \mathrm{~kg}^{-1}$ (monkeys), and the volume of distribution was $1.47-2.49 \mathrm{~L} \mathrm{~kg}^{-1}$ (rats) and 2.79-3.69 $\mathrm{L} \mathrm{kg}^{-1}$ (monkeys) [13]. In a phase 1 study, after a single oral administration of esaxerenone in healthy Japanese subjects, doseproportional exposure was generally evident up to $200 \mathrm{mg}$ with no clinically significant safety concerns [14]. Similarly, in a phase 2, randomised, controlled study, plasma esaxerenone concentrations increased in proportion to dose (1.25-5 mg per day) [12].

Studies assessing the absolute bioavailability and the effects of food on pharmacokinetics (PK) are important during new compound evaluation [15]. The purpose of the current phase 1 study in healthy Japanese subjects was to assess the absolute bioavailability of esaxerenone after administration of a single oral dose. This study also assessed the effect of food on the PK of esaxerenone administered as a single oral dose, as well as the PK and safety of esaxerenone administered as a single oral or IV dose in the fasting state and as a single oral dose in the postprandial state.

\section{METHODS}

\section{Study Design and Treatments}

This was a single-centre, open-label, single-dose, three-way, three-period crossover study in healthy Japanese subjects, conducted at the Osaka Pharmacology Clinical Research Hospital, Osaka, Japan. The design, based on a Williams Latin square [16], comprised six study groups, each containing four subjects; an 8-day treatment washout was included between each of the three study periods (Fig. 1).

Esaxerenone was administered as follows: one 5-mg tablet, orally, in the fasting state (fasting for $\geq 10 \mathrm{~h}$ before administration); or IV infusion of a $100-\mathrm{mL}$ solution $\left(0.05 \mathrm{mg} \mathrm{mL}^{-1}\right.$ in $5 \%$ glucose solution) over $1 \mathrm{~h}$ in a fasting state; or one 5-mg tablet, orally with $200 \mathrm{~mL}$ of water, in the postprandial state $(30 \mathrm{~min}$ after consumption of a high-fat, high-calorie meal) [15]. No beverages could be consumed $1 \mathrm{~h}$ before or $2 \mathrm{~h}$ after study drug administration. Subjects rested in a sitting position for $4 \mathrm{~h}$ after drug administration. Caffeinated drinks were not 


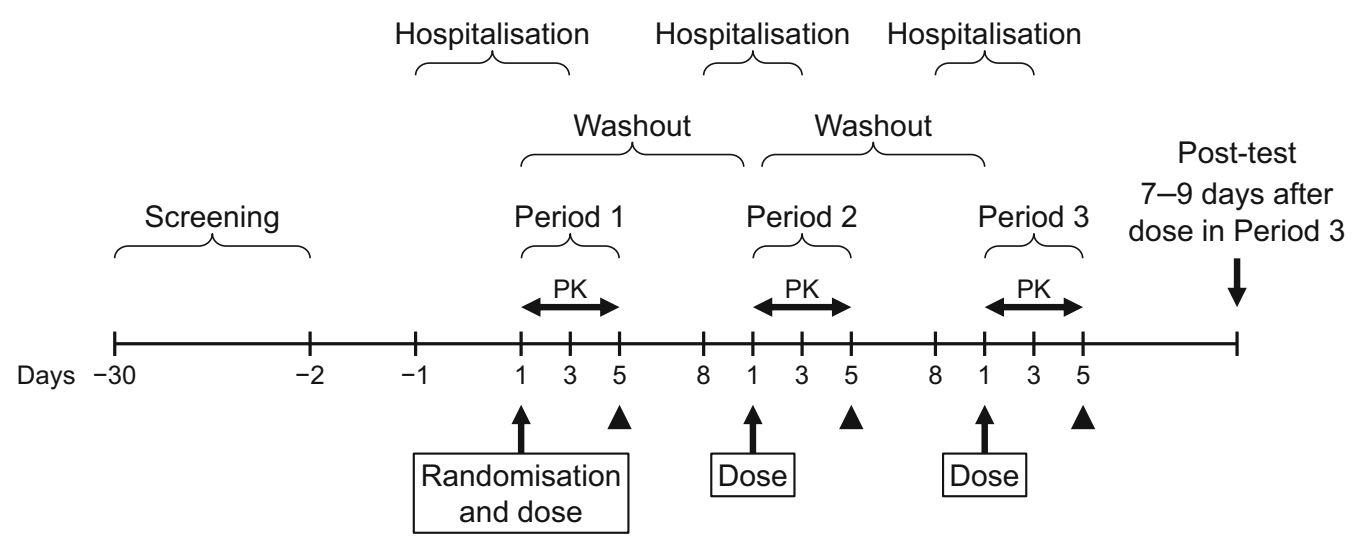

$\boldsymbol{\Delta}$ : visits

Fig. 1 Study design. PK, pharmacokinetics. Washout period between doses was 8 days

allowed during the hospitalisation period (4 days and 3 nights), and subjects were only permitted food prepared by the study centre and provided at a predetermined time. Subjects returned to the study centre for a follow-up examination 7-9 days after study drug administration.

The oral esaxerenone dose was set at $5 \mathrm{mg}$ because this was the maximum dose for which esaxerenone efficacy and safety had been confirmed in a previous phase 2 study in patients with essential hypertension [12]. The IV esaxerenone dose was also set at $5 \mathrm{mg}$, based on previous safety data from healthy Japanese subjects [14].

The study was conducted in accordance with Good Clinical Practice, the ethical principles of the Declaration of Helsinki, and with the Pharmaceuticals Affairs Law, and the Ordinances Regarding Good Clinical Practice of the Ministry of Health, Labour and Welfare, Japan. The study was reviewed and approved by the Osaka Pharmacology Clinical Research Hospital institutional review board (16 December 2016; 978BA). The study was registered with Japan Pharmaceutical Information Center Clinical Trials Information (JapicCTI) (www. clinicaltrials.jp; JapicCTI-163452). All subjects provided written informed consent to participate.

\section{STUDY SUBJECTS}

All subjects were healthy Japanese males aged $20-45$ years, with a body mass index of 18.5 to $<25.0 \mathrm{~kg} \mathrm{~m}^{-2}$, sitting BP of $<140 /$ $90 \mathrm{mmHg}$, and a pulse rate of $\leq 99$ beats $\mathrm{min}^{-1}$.

Exclusion criteria comprised: a history of a serious disease affecting the central nervous, cardiovascular, respiratory, blood/haematopoietic, gastrointestinal, or hepatorenal system, or thyroid, pituitary, or adrenal function; drug hypersensitivity or idiosyncratic reactions (e.g. penicillin allergy); drug or alcohol dependence; positive hepatitis B surface antigen, hepatitis C virus antibody, syphilis, or HIV antibody infection test results; collection of $\geq 1200 \mathrm{~mL}$ of whole blood within the previous year, $\geq 400 \mathrm{~mL}$ of whole blood collected within the last 84 days, or $\geq 200 \mathrm{~mL}$ collected in the 28 days prior to screening, or plasmapheresis or platelet apheresis within 14 days before screening; participation in another clinical study and receipt of an investigational drug within 120 days before screening; previous participation in a clinical study of esaxerenone; receiving concomitant therapy (including foods or supplements containing St John's wort) within the previous 30 days or had planned use during the study period; any clinically significant findings at screening (including headache), abnormal electrocardiography (ECG), and deviations in laboratory data from the reference range of the study 
centre (including serum potassium levels); and having difficulty with participation in the study (for example, if visiting the study centre seemed difficult).

\section{PK ASSESSMENTS}

For measuring plasma drug concentrations, $3 \mathrm{~mL}$ of venous blood was drawn into a vacuum tube containing ethylenediaminetetraacetic acid dipotassium salt at each time point. Blood sampling time points were: before and at $0.5,1$, $1.5,2,2.5,3,3.5,4,8,24,48$, and $96 \mathrm{~h}$ (oral administration), and before and at $0.25,0.5,1$, $2,3,4,8,24,48$, and $96 \mathrm{~h}$ after the start of the IV infusion. Plasma obtained by centrifugation (at $4{ }^{\circ} \mathrm{C}$ and $1700 \mathrm{~g}$ for $10 \mathrm{~min}$ ) was separated into two storage containers containing approximately $0.5 \mathrm{~mL}$, which were then frozen ( $-20^{\circ} \mathrm{C}$ or lower) until ready to be transferred on dry ice to the central drug concentration measurement facility. Drug concentrations were measured by liquid chromatography-tandem mass spectrometry (LC-MS/MS). Chromatographic separation was performed using a CAPCELL PAKC18 MGIII (Shiseido, Tokyo, Japan) column $(2.0 \times 150 \mathrm{~mm}, 5 \mu \mathrm{m})$. An API 4000 (AB SCIEX; Framingham, MA, USA) tandem mass spectrometer was used for detection, with TurboIonSpray source by electrospray ionisation in the negative ion mode and multiple-reaction monitoring of esaxerenone $(\mathrm{m} / \mathrm{z}$ 465-365) and its internal standard $(\mathrm{m} / \mathrm{z}$ 472-370), as described previously [14]. For esaxerenone test samples of 0.3, 4.0, and $80.0 \mathrm{ng} \mathrm{mL}^{-1}$, intra-study assay precision was $3.7 \%, 3.7 \%$, and $3.5 \%$, respectively. Accuracy of the assay ranged from $1.0 \%$ to $0.3 \%$, with a lower limit of quantification of $0.1 \mathrm{ng} \mathrm{mL}^{-1}$ and a linear range of 0.1 to $100 \mathrm{ng} \mathrm{mL}^{-1}$.

The following esaxerenone PK parameters were calculated by noncompartmental analysis: oral administration-peak plasma concentration $\left(\mathrm{C}_{\max }\right)$, area under the plasma concentration-time curve (AUC) from time zero to time of the last measurable concentration $\left(\mathrm{AUC}_{\text {last }}\right)$, AUC from time zero to infinity $\left(\mathrm{AUC}_{\text {inf }}\right)$, time to reach $C_{\max }\left(t_{\max }\right)$, elimination half-life $\left(t_{1 / 2}\right)$, apparent total body clearance $(\mathrm{CL} / \mathrm{F})$, and apparent volume of distribution based on the terminal phase $\left(\mathrm{V}_{\mathrm{z}} / \mathrm{F}\right)$; and IV administration$\mathrm{C}_{\max }, \mathrm{AUC}_{\text {last}}, \mathrm{AUC}_{\mathrm{inf}}, t_{\max }, t_{1 / 2}$, total body clearance $(\mathrm{CL})$, volume of distribution during the terminal phase $\left(\mathrm{V}_{\mathrm{z}}\right)$, and volume of distribution at steady state $\left(\mathrm{V}_{\mathrm{ss}}\right)$. For the food-effect evaluation, $\mathrm{C}_{\max }$ and $\mathrm{AUC}_{\text {last }}$ were used as the primary endpoints. Using $\mathrm{AUC}_{\mathrm{inf}}$ obtained under each dosing condition, the absolute bioavailability $(\mathrm{F}, \%)$ of oral esaxerenone (fasting and postprandial) was calculated according to the following formula:

$$
F=\frac{\operatorname{AUC}_{(\mathrm{po})}}{\mathrm{AUC}_{(\mathrm{iv})}} \times 100 .
$$

\section{SAFETY ASSESSMENTS}

Safety endpoints were AEs, laboratory tests, vital signs (BP, pulse rate, body temperature), and ECG findings. All were evaluated upon hospitalisation (day before study drug administration), immediately before drug administration, and at the end of the study. During follow-up, vital signs were evaluated at 1, 2, 4 and 7-9 days after drug administration, ECG at 4 and 7-9 days after drug administration, and laboratory findings three times each at the following times: upon hospitalisation (day before study drug administration), and 4 and 7-9 days after drug administration. Individual AEs were categorised in accordance with Medical Dictionary for Regulatory Activities (MedDRA/J v.19.1) System Organ Class and Preferred Terms.

\section{SAMPLE SIZE}

US Food and Drug Administration guidance for assessment of the effects of food on PK [15] recommends a sample size of at least 12 subjects to ensure a statistical power sufficient to statistically demonstrate the absence of a food effect. In a pilot food-effect study of esaxerenone, intra-individual variabilities (coefficient of variation) were $14.8 \%$ for $C_{\max }$ and $7.3 \%$ for AUC (unpublished data on file; Daiichi Sankyo). Therefore, in the present study, intra-individual variabilities were estimated to be $20 \%$ for $C_{\max }$ 
and $10 \%$ for AUC. Assuming the absence of a food effect (estimated geometric mean ratios for $\mathrm{C}_{\max }$ and AUC 0.95-1.05), the statistical power to verify equivalence is $\geq 80 \%$ if the sample size of 18 subjects (three per group) is fulfilled. Thus, based on these assumptions and considering potentially unexpected situations such as dropouts, the sample size for the current study was set at 24 subjects (four per group).

\section{STATISTICAL ANALYSES}

For $\mathrm{AUC}_{\text {inf }}$ compared between two dosing conditions in each of the two pairs (fasting oral vs. IV administration; postprandial oral vs. fasting IV administration), the geometric least squares mean (GLSM) ratio between two dosing conditions in each of the two pairs and the two-sided 95\% confidence intervals (CIs) were calculated.
For $\mathrm{C}_{\max }$ and $\mathrm{AUC}_{\text {last }}$ after fasting and postprandial oral administration, the GLSM in each dosing condition, and the GLSM ratio between the two dosing conditions (postprandial vs. fasting oral administration), and two-sided 90\% CIs were calculated.

The PK analysis set comprised subjects who received the study drug under at least two of the three dosing conditions: subjects with data available for either $\mathrm{C}_{\max }$ or $\mathrm{AUC}_{\text {last }}$ after oral administration, or subjects with data evaluable for absolute bioavailability after oral administration. The safety analysis set comprised all subjects who received a dose of the study drug. Statistical analyses were performed using SAS System Release 9.2 software (SAS Institute, Cary, NC, USA), and PK analyses were performed using Phoenix ${ }^{\circledR}$ WinNonlin $^{\circledR}$ v.6.3 software (Certara USA, Princeton, NJ, USA).

Table 1 Pharmacokinetic parameters of $5 \mathrm{mg}$ esaxerenone in healthy Japanese subjects

\begin{tabular}{llll}
\hline PK parameters & \multicolumn{2}{l}{ Dosing conditions } & \\
\cline { 2 - 4 } & $\begin{array}{l}\text { Fasting oral } \\
\text { administration } \boldsymbol{n}=\mathbf{2 3}\end{array}$ & $\begin{array}{l}\text { Postprandial oral } \\
\text { administration } \boldsymbol{n}=\mathbf{2 3}\end{array}$ & $\begin{array}{l}\text { Fasting IV } \\
\text { administration } \boldsymbol{n}=\mathbf{2 3}\end{array}$ \\
\hline $\mathrm{C}_{\mathrm{max}}\left(\mathrm{ng} \mathrm{mL}^{-1}\right)$ & $64.9(12.1)$ & $65.2(9.6)$ & $127(18.3)$ \\
$\mathrm{AUC}_{\text {last }}\left(\mathrm{ng} \mathrm{h} \mathrm{mL}^{-1}\right)$ & $1200(174)$ & $1220(170)$ & $1360(227)$ \\
$\mathrm{AUC}_{\text {inf }}\left(\mathrm{ng} \mathrm{h} \mathrm{mL}^{-1}\right)$ & $1230(187)$ & $1260(186)$ & $1390(245)$ \\
$t_{\max }(\mathrm{h})^{\mathrm{a}}$ & $3.00(1.50,4.00)$ & $2.50(1.50,4.00)$ & $0.98(0.98,0.98)$ \\
$t_{1 / 2}(\mathrm{~h})$ & $18.6(2.38)$ & $18.7(2.10)$ & $17.6(1.84)$ \\
$\mathrm{CL} / \mathrm{F}\left(\mathrm{L} \mathrm{h}^{-1}\right)$ & $4.13(0.55)$ & $4.05(0.51)$ & - \\
$\mathrm{CL}\left(\mathrm{L} \mathrm{h} \mathrm{h}^{-1}\right)$ & - & - & $3.69(0.55)$ \\
$\mathrm{V}_{\mathrm{z}} / \mathrm{F}(\mathrm{L})$ & $110(17.5)$ & $109(14.8)$ & - \\
$\mathrm{V}_{\mathrm{z}}(\mathrm{L})$ & - & - & $92.7(11.8)$ \\
$\mathrm{V}_{\mathrm{ss}}(\mathrm{L})$ & - & - & $80.2(9.50)$ \\
\hline
\end{tabular}

Values are mean (standard deviation), unless otherwise stated

'-' indicates not calculated; $A U C$ area under the curve; $C L$ total body clearance from plasma; $C L / F$ apparent total body clearance from plasma after oral administration; $C_{\max }$ peak plasma concentration; $I V$ intravenous; $P K$ pharmacokinetic; $t_{1 / 2}$ elimination half-life; $t_{\max }$ time to $C_{\max } ; V_{\mathrm{ss}}$ volume of distribution at steady state; $V_{\mathrm{z}}$ volume of distribution based on the terminal phase; $V_{\mathrm{z}} / F$ apparent volume of distribution based on the terminal phase after oral administration

${ }^{a}$ Values are median (range) 

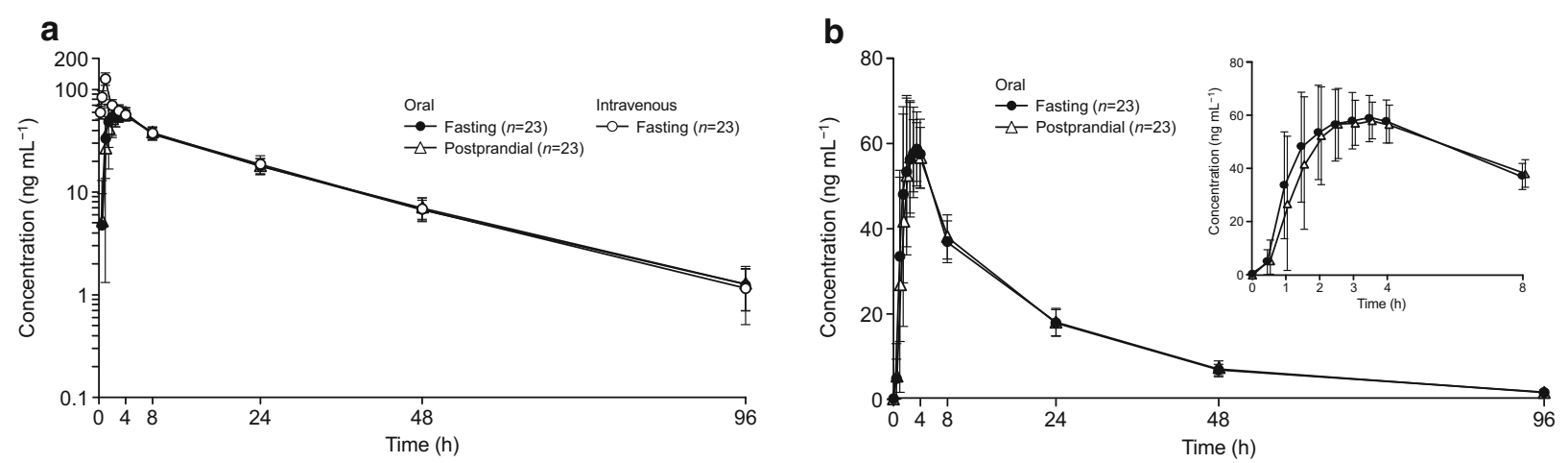

Fig. 2 Time course of the mean plasma concentration of esaxerenone: a semi-log plot of $5 \mathrm{mg}$ oral administration (fasting and postprandial state) or intravenous administration $\left(0.05 \mathrm{mg} \mathrm{mL}^{-1}\right.$ solution $100 \mathrm{~mL}, 1-\mathrm{h}$ infusion; fasting state); and b linear plot of oral administration of $5 \mathrm{mg}$ tablets (fasting and postprandial state; inset shows the linear plot over $8 \mathrm{~h}$; pharmacokinetic analysis set). Data are means \pm standard deviations

\section{RESULTS}

\section{Subject Disposition}

All 24 subjects who received the study drug were included in the safety analysis set. One subject discontinued the study during Period 1 because of an $\mathrm{AE}$ and did not have PK data after discontinuation; this subject was excluded from the PK analysis set, which therefore comprised 23 subjects (Table 1). Baseline characteristics (mean, standard deviation) were: age 26.0 (4.4) years, bodyweight $63.1(6.0) \mathrm{kg}$, and body mass index 21.3 (1.6) $\mathrm{kg} \mathrm{m}^{-2}$.

\section{PK Endpoints}

Plasma drug concentrations increased gradually during continuous IV administration ( $1 \mathrm{~h}$ ) of esaxerenone $5 \mathrm{mg}$, peaked at the end of infusion, and then decreased with a $t_{1 / 2}$ of $17.6 \mathrm{~h}$ (arithmetic mean) (Fig. 2a). Full details of esaxerenone PK parameters after oral (fasting, postprandial) and IV administration are shown in Table 1. Changes over time in plasma esaxerenone concentrations after a single oral dose of $5 \mathrm{mg}$ were similar after fasting and postprandial administration (Fig. 2a, b). In addition, PK parameters were similar after fasting and postprandial esaxerenone administration (Table 1). Esaxerenone showed good bioavailability after oral administration (Table 2). The
90\% CI values for GLSM ratios of PK parameters obtained after postprandial versus fasting oral administration were within the pre-specified range $(0.80,1.25)$ for which food intake was judged not to affect esaxerenone PK (Table 2).

\section{Safety}

No deaths or serious AEs occurred. There were a total of 10 AEs in 9 of the 24 subjects enrolled (incidence 29.2\%; Table 3). 'Presyncope' led to treatment discontinuation in one subject after fasting oral administration. Mood disorder and facial pallor appeared 15 min after oral administration and both disappeared after $11 \mathrm{~min}$ of treatment (leg elevation). The event was moderate in severity and was assessed as being related to treatment because a potential association could not be denied. All other AEs were mild and considered by the investigator to be 'not related' to treatment. All AEs resolved within the study period, and there were no cases of abnormal laboratory test values or abnormal ECG findings.

\section{DISCUSSION}

This phase 1 study defined the absolute bioavailability of single $5-\mathrm{mg}$ oral doses of esaxerenone in healthy Japanese adult males and evaluated the effects of food on esaxerenone PK and safety after a single 5-mg oral 
Table 2 Bioavailability of esaxerenone and effects of food on esaxerenone pharmacokinetics

\begin{tabular}{|c|c|c|c|c|}
\hline \multirow[t]{2}{*}{ Bioavailability } & \multicolumn{2}{|c|}{ Geometric least squares mean } & \multirow{2}{*}{$\begin{array}{l}\text { Ratio } \\
\text { Oral/IV }\end{array}$} & \multirow[t]{2}{*}{$90 \% \mathrm{CI}$} \\
\hline & Oral administration & IV administration & & \\
\hline \multicolumn{5}{|l|}{$\mathrm{AUC}_{\text {inf }}\left(\mathrm{ng} \mathrm{h} \mathrm{mL} \mathrm{mL}^{-1}\right)$} \\
\hline Fasting & 1224.33 & 1374.99 & 89.0 & $86.7,91.5$ \\
\hline Postprandial & 1247.86 & - & 90.8 & $88.3,93.2$ \\
\hline \multirow[t]{2}{*}{ Effect of food } & \multicolumn{2}{|c|}{ Geometric least squares mean } & Ratio & $90 \% \mathrm{CI}$ \\
\hline & $\begin{array}{l}\text { Postprandial oral } \\
\text { administration }\end{array}$ & $\begin{array}{l}\text { Fasting oral } \\
\text { administration }\end{array}$ & $\begin{array}{l}\text { Postprandial/ } \\
\text { fasting }\end{array}$ & \\
\hline $\mathrm{C}_{\max }\left(\mathrm{ng} \mathrm{mL^{-1 }}\right)$ & 64.40 & 63.75 & 1.010 & $0.951,1.073$ \\
\hline $\mathrm{AUC}_{\text {last }}\left(\mathrm{ng} \mathrm{h} \mathrm{mL} \mathrm{m}^{-1}\right)$ & 1212.84 & 1190.66 & 1.019 & $0.995,1.042$ \\
\hline
\end{tabular}

$A U C$ area under the curve; $C_{\max }$ peak plasma concentration; $C I$ confidence interval; $I V$ intravenous

a Presented as ratio $(\times 100) \%$

Table 3 Number of subjects with adverse events

\begin{tabular}{|c|c|c|c|}
\hline & \multicolumn{3}{|l|}{ Dosing conditions } \\
\hline & $\begin{array}{l}\text { Fasting oral } \\
\text { administration } n=24\end{array}$ & $\begin{array}{l}\text { Postprandial oral } \\
\text { administration } n=23\end{array}$ & $\begin{array}{l}\text { Fasting IV } \\
\text { administration } n=23\end{array}$ \\
\hline All AEs & $3(12.5)$ & $2(8.7)$ & $4(17.4)$ \\
\hline $\begin{array}{l}\text { Infectious and parasitic } \\
\text { diseases }\end{array}$ & $1(4.2)$ & $1(4.3)$ & $1(4.3)$ \\
\hline Nasopharyngitis & $1(4.2)$ & $1(4.3)$ & $1(4.3)$ \\
\hline Nervous system disturbances & $1(4.2)$ & $0(0.0)$ & $1(4.3)$ \\
\hline Headache & $0(0.0)$ & $0(0.0)$ & $1(4.3)$ \\
\hline Presyncope & $1(4.2)$ & $0(0.0)$ & $0(0.0)$ \\
\hline Laboratory test abnormalities & $1(4.2)$ & $1(4.3)$ & $2(8.7)^{\mathrm{a}}$ \\
\hline $\begin{array}{l}\text { Increased aspartate } \\
\text { aminotransferase }\end{array}$ & $0(0.0)$ & $0(0.0)$ & $1(4.3)$ \\
\hline $\begin{array}{l}\text { Increased blood creatine } \\
\text { phosphokinase }\end{array}$ & $1(4.2)$ & $0(0.0)$ & $1(4.3)$ \\
\hline Increased C-reactive protein & $0(0.0)$ & $1(4.3)$ & $1(4.3)$ \\
\hline
\end{tabular}

All terminologies adhere to MedDRA/J (v.19.1). Data are number (\%)

$A E$ adverse event; $I V$ intravenous

${ }^{a}$ One subject experienced both an increase in blood creatine phosphokinase and an increase in aspartate aminotransferase 
dose. We found that the absolute bioavailability of esaxerenone was high $(\sim 90 \%)$ and concurrent meal ingestion had no effect on esaxerenone PK.

Importantly, the low CL $\left(0.97 \mathrm{~mL} \mathrm{~min}^{-1} \mathrm{~kg}^{-1}\right)$, large $\mathrm{V}_{\mathrm{ss}}\left(1.27 \mathrm{~L} \mathrm{~kg}^{-1}\right)$ and high absolute bioavailability $(89.0 \%)$ values identified for esaxerenone in humans (fasting) in our study are similar to values obtained in animal studies. Furthermore, the absolute bioavailability of esaxerenone after a single oral dose (0.1-3.0 $\mathrm{mg} \mathrm{kg}^{-1}$ ) was high: $61-127 \%$ in rats and 64-74\% in cynomolgus monkeys [13]. These findings suggest that esaxerenone has high membrane permeability and a small, if any, firstpass effect because of low intrinsic clearance. Animal PK data [13], together with our study results, also indicate that esaxerenone is widely distributed in tissues of both animals and humans, because distribution volume was greater than the extracellular fluid volume.

We also investigated the effects of food on esaxerenone $\mathrm{PK}$ with esaxerenone $5 \mathrm{mg}$, the highest esaxerenone dose evaluated in phase 3 (ClinicalTrials.gov identifier: NCT02890173). At a dose of $5 \mathrm{mg}$, esaxerenone is approximately $50 \%$ soluble in a $250-\mathrm{mL}$ aqueous solution [solubility $\sim 10 \mu \mathrm{g} \mathrm{mL}^{-1}$ in water (unpublished data on file; Daiichi Sankyo)]. Esaxerenone has high membrane permeability, as evidenced by high absolute bioavailability, which means that it falls within Biopharmaceutics Classification System class 2. Class 2 drugs are defined as having low solubility and high membrane permeability, and absorption may be increased by a high-fat meal, due to increased bile release, bile salt and micellar solubilisation activity, and enhanced drug dissolution [17, 18]. As such, doses of esaxerenone much greater than $5 \mathrm{mg}$ may be affected by diet (i.e. esaxerenone absorption might be increased by food). However, in our study with a 5-mg dose of esaxerenone, 90\% CIs for GLSM ratios for $\mathrm{C}_{\max }$ and $\mathrm{AUC}_{\text {last }}$ after postprandial versus fasting oral esaxerenone administration were within the prespecified range $(0.80,1.25)$, indicating that food intake does not affect esaxerenone PK at anticipated clinical doses. The principal reason for the lack of a food effect is thought to be that esaxerenone is gradually dissolved and absorbed in the gastrointestinal tract, and is eventually almost completely absorbed, even in the fasting state.

In a previous mass balance study of orally administered $\left[{ }^{14} \mathrm{C}\right]$ esaxerenone $(150 \mu \mathrm{Ci}$ per $20 \mathrm{mg}$ ) in healthy non-Japanese adult subjects, excretion of unchanged esaxerenone in faeces was $18.7 \%$ of the administered dose (total excretion of radioactivity was 92.5\%) [19], which indicated a fraction absorbed of $>80 \%$. Yamada et al. [19] hypothesised that the absorption ratio would be much higher than $80 \%$ because unchanged esaxerenone excreted in the faeces was likely to include the deconjugated O-glucuronide of esaxerenone excreted via bile. This hypothesis was supported by the finding of high absolute bioavailability for esaxerenone in the current study.

Esaxerenone was well tolerated in this study: no serious AEs occurred; the route of esaxerenone administration, and the fasting or fed state, had no influence on the incidence of AEs; and there were no clinically significant alterations in vital signs, bodyweight, or 12-lead ECG.

\section{CONCLUSIONS}

In conclusion, esaxerenone had low total body clearance and a high volume of distribution in healthy Japanese subjects. A single oral dose of $5 \mathrm{mg}$ esaxerenone had a high absolute bioavailability of approximately 90\%. The absence of a food effect on esaxerenone PK was demonstrated in this population as the $90 \%$ CIs for GLSM ratios for $\mathrm{C}_{\max }$ and $\mathrm{AUC}_{\text {last }}$ after esaxerenone administration in postprandial versus fasting states were within the prespecified range (0.80-1.25). No safety concerns were identified.

\section{ACKNOWLEDGEMENTS}

Funding. This study was funded by Daiichi Sankyo Co., Ltd. All authors had full access to all of the study data and take complete 
responsibility for the integrity of the data and accuracy of the data analysis.

Authorship. All authors approved the final manuscript before submission. All named authors meet the International Committee of Medical Journal Editors (ICMJE) criteria for authorship for this article, take responsibility for the integrity of the work as a whole, and have given their approval for this version to be published.

Authorship Contributions. All authors contributed to the writing of the manuscript, design and implementation of the research and provided critical feedback on the manuscript.

Medical Writing, Editorial, and Other Assistance. The authors wish to thank Tsunenori Nakazawa for providing support with the bioanalysis of this study. The authors would also like to thank: Natsuki Tanaka, Naoko Suzuki, Saiko Yamada, and Kayo Matsumoto (clinical research coordinators at the study site); Yuko Kotani and Saeko Fukushima (nurses at the study site); and David Murdoch and Emma Donadieu of Edanz Medical Writing for providing medical writing services, which were funded by Daiichi Sankyo Co., Ltd.

Disclosures. Akifumi Kurata is an employee of Daiichi Sankyo Co., Ltd. Tomoko Ishizuka is an employee of Daiichi Sankyo Co., Ltd. Takafumi Nakatsu is an employee of Daiichi Sankyo Co., Ltd. Takako Shimizu is an employee of Daiichi Sankyo Co., Ltd. Manabu Kato is an employee of Daiichi Sankyo Co., Ltd. Yasuhiro Nishikawa is an employee of Daiichi Sankyo Co., Ltd. Hitoshi Ishizuka is an employee of Daiichi Sankyo Co., Ltd. Hidetoshi Furuie received research funding for this study from Daiichi Sankyo Co., Ltd.

Compliance with Ethics Guidelines. All procedures performed in studies involving human participants were in accordance with the ethical standards of the Pharmaceuticals Affairs Law, the Ordinances Regarding Good Clinical Practice of the Ministry of Health, Labour and Welfare, Japan and with the 1964
Helsinki declaration and its later amendments or comparable ethical standards. Informed consent was obtained from all individual participants included in the study. The study was reviewed and approved by the Osaka Pharmacology Clinical Research Hospital institutional review board (16 December 2016; 978BA). Springer's policy concerning informed consent has been followed.

Data Availability. The datasets generated during and/or analysed during the current study are available from the corresponding author on reasonable request.

Open Access. This article is distributed under the terms of the Creative Commons Attribution-NonCommercial 4.0 International License (http://creativecommons.org/licenses/ by-nc/4.0/), which permits any noncommercial use, distribution, and reproduction in any medium, provided you give appropriate credit to the original author(s) and the source, provide a link to the Creative Commons license, and indicate if changes were made.

\section{REFERENCES}

1. Shimamoto K, Ando K, Fujita T, et al. The Japanese Society of hypertension guidelines for the management of hypertension (JSH 2014). Hypertens Res. 2014;37:253-390. https://doi.org/10.1038/hr. 2014.20.

2. Chobanian AV, Bakris GL, Black HR, et al. Seventh report of the joint national committee on prevention, detection, evaluation, and treatment of high blood pressure. Hypertension. 2003;42:1206-52. https://doi.org/10.1161/01.HYP.0000107251.49515. c2.

3. Tedesco MA, Natale F, Calabro R. Effects of monotherapy and combination therapy on blood pressure control and target organ damage: a randomized prospective intervention study in a large population of hypertensive patients. J Clin Hypertens (Greenwich). 2006;8:634-41.

4. Mancia G, Fagard R, Narkiewicz K, et al. 2013 ESH/ ESC guidelines for the management of arterial hypertension. Eur Heart J. 2013;34:2159-219. 
5. Dahal K, Kunwar S, Rijal J, et al. The effects of aldosterone antagonists in patients with resistant hypertension: a meta-analysis of randomized and nonrandomized studies. Am J Hypertens. 2015;28: 1376-85. https://doi.org/10.1093/ajh/hpv031.

6. Williams B, MacDonald TM, Morant S, et al. Spironolactone versus placebo, bisoprolol, and doxazosin to determine the optimal treatment for drug-resistant hypertension (PATHWAY-2): a randomised, double-blind, crossover trial. Lancet. 2015;386:2059-68. https://doi.org/10.1016/S01406736(15)00257-3.

7. Shibata H, Itoh H. Mineralocorticoid receptor-associated hypertension and its organ damage: clinical relevance for resistant hypertension. Am J Hypertens. 2012;25:514-23. https://doi.org/10. 1038/ajh.2011.245.

8. Epstein M, Duprez DA. Resistant hypertension and the pivotal role for mineralocorticoid receptor antagonists: a clinical update 2016. Am J Med. 2016;129:661-6. https://doi.org/10.1016/j.amjmed. 2016.01.039.

9. Takahashi S, Katada J, Daida H, Kitamura F, Yokoyama K. Effects of mineralocorticoid receptor antagonists in patients with hypertension and diabetes mellitus: a systematic review and meta-analysis. J Hum Hypertens. 2016;30:534-42. https://doi. org/10.1038/jhh.2015.119.

10. Narayan H, Webb DJ. New evidence supporting the use of mineralocorticoid receptor blockers in drugresistant hypertension. Curr Hypertens Rep. 2016;18:34. https://doi.org/10.1007/s11906-0160643-8.

11. Arai K, Tsuruoka H, Homma T. CS-3150, a novel non-steroidal mineralocorticoid receptor antagonist, prevents hypertension and cardiorenal injury in Dahl salt-sensitive hypertensive rats. Eur J Pharmacol. 2015;769:266-73. https://doi.org/10.1016/j. ejphar.2015.11.028.

12. Ito $\mathrm{S}$, Itoh $\mathrm{H}$, Rakugi $\mathrm{H}$, Okuda $\mathrm{Y}$, Yamakawa $\mathrm{S}$. Treatment with esaxerenone (CS-3150) is associated with a significant dose-dependent antihypertensive effect in essential hypertensive patients. J Hypertens. 2017;35:e173. https://doi.org/10.1097/01.hjh. 0000523471.25362.f5.
13. Yamada M, Takei M, Suzuki E, et al. Pharmacokinetics, distribution, and disposition of esaxerenone, a novel, highly potent and selective non-steroidal mineralocorticoid receptor antagonist, in rats and monkeys. Xenobiotica. 2017;47:1090-103. https:// doi.org/10.1080/00498254.2016.1263766.

14. Kato M, Furuie H, Shimizu T, Miyazaki A, Kobayashi F, Ishizuka H. Single- and multiple-dose escalation study to assess pharmacokinetics, pharmacodynamics and safety of oral esaxerenone in healthy Japanese subjects. Br J Clin Pharmacol. 2018;84: 1821-9. https://doi.org/10.1111/bcp.13616.

15. US Department of Health and Human Services, Food and Drug Administration, Center for Drug Evaluation and Research (CDER). 2002. Guidance for industry food effect bioavailability and fed bioequivalence studies. https://www.fda.gov/down loads/drugs/guidancecomplianceregulatoryinforma tion/guidances/ucm070241.pdf. Accessed 18 Feb 2019.

16. Jones B, Kenward MG. Design and analysis of crossover trials. 2nd ed. London: Chapman \& Hall; 2003.

17. Fleisher D, Li C, Zhou Y, Pao LH, Karim A. Drug, meal and formulation interactions influencing drug absorption after oral administration. Clinical implications. Clin Pharmacokinet. 1999;36:233-54. https://doi.org/10.2165/00003088-199936030-00 004 .

18. US Department of Health and Human Services. Food and Drug Administration. Center for Drug Evaluation and Research (CDER). 2017. Biopharmaceutics. Waiver of in vivo bioavailability and bioequivalence studies for immediate-release solid oral dosage forms based on a biopharmaceutics classification system. Guidance for industry. https://www.fda.gov/downloads/Drugs/Guidances/ ucm070246.pdf. Accessed 14 Sept 2018.

19. Yamada M, Mendell H, Takakusa $H$, Shimizu $T$, Ando O. Pharmacokinetics, metabolism, and excretion of [14C]esaxerenone, a novel mineralocorticoid receptor blocker in humans. Drug Metab Dispos. 2018;47:340-9. https://doi.org/10.1124/ dmd.118.084897. 